\title{
Alt Karın Duvarı Kaynaklı Fleplerin Donor Alanı Kapamasında Dermal Geri Dönüşüm Grefti ile Klinik Deneyim
}

\author{
Semih Bağhaki
}

İstanbul Üniversitesi, Cerrahpaşa Tıp Fakültesi, Plastik, Rekonstrüktif ve Estetik Cerrahi Anabilim Dalı, İstanbul, Türkiye

Bağhaki Semih

İletişim:

Semih Bağhaki

İstanbul Üniversitesi, Cerrahpașa Tıp Fakültesi, Plastik, Rekonstrüktif ve Estetik Cerrahi Anabilim Dall, İstanbul, Türkiye

E-Posta: semihbaghaki@yahoo.com

Gönderilme Tarihi : 24 Ekim 2017

Revizyon Tarihi : 12 Kasım 2017

Kabul Tarihi : 21 Kasım 2017
ÖZET

Amaç: Pediküllü TRAM flepten perforatör bazlı DiEP flebe kadar tüm alt karın duvarı kaynakı flepler değişen derecelerde karın duvarı morbiditesine neden olur. Fasya onarımını desteklemek için göreceli olarak az kanlanan ve dolayısıyla kullanıımayan flep kısmının dezepitelizasyonu ve lipektomisi sonucu ortaya çıkarılan dermal greftin kullanıılığı olgu serisi ve uzun dönem sonuçlar bu yazıda sunulmuştur.

Çalışma Planı: Eylül 2012 ve Ağustos 2016 arasında alt karın kaynaklı fleplerle meme rekonstrüksiyonu uygulanmış toplam 33 kadın hastanın hasta dosyaları geriye dönük olarak incelenmiştir. Demografik bilgiler, fotografik dokümentasyon, ameliyat raporları, kontrol vizitlerinde tutulan notlar ve hastaların uzun döneme ait sübjektif değerlendirmeleri derlenmiştir.

Bulgular: Eylül 2012 ve Ağustos 2016 arasında meme rekonstrüksiyonu uygulanmış toplam 33 kadın hastanın yaş aralığı 35 - 56 ve yaş ortalaması 43 idi. Hastaların 22'si premenopozal, 11'i postmenopozal idi. Hastaların vücut-kitle endeksleri 26,2 ile 34,6 arasında değişmekte ve ortalama 28,8 idi. Hastaların $14^{\prime}$ üne eşzamanlı meme rekonstrüksiyonu, $19^{\prime}$ una geç meme rekonstrüksiyonu uygulanmıştı. Hastaların 21'ine pediküllü TRAM flep, 5'ine serbest TRAM flep, 4'üne serbest kas koruyucu TRAM flep ve $3^{\prime}$ 'üne serbest DIEP flep uygulanmıştı. Takip süreleri 1 yıl ile 3 yıl arasında ve ortalama 15 ay idi. Hastaların hiçbirinde uzun dönemde herni gelişmedi. İki hastada (\%6) donor alanda şişlik tespit edildi ve bu hastalardan birinde fasya tamiri yapıldı. Hastaların hiçbirinde enfeksiyon veya yabancı cisim reaksiyonu gelişmedi. Kontrol vizitlerinde hastaların tümü aktif karın fleksiyonu gerektiren günlük olaylarda herhangi bir zorluk yaşamadıklarııı ifade etmişlerdir.

Sonuç: Alt karın duvarı kaynaklı fleplerin kullanılmayan kısmından hazırlanan dermal "geri dönüşüm” grefti bu fleplerin donor alanının tamirinde pratik ve başarılı sonuçlar ortaya koymaktadır.

Anahtar sözcükler: Dermal, greft, meme rekonstrüksiyonu

\section{A CLINICAL EXPERIENCE WITH CLOSURE OF THE DONOR SITE FOLLOWING LOWER ABDOMINAL WALL FLAP WITH DERMAL} RECYCLING GRAFT

\section{ABSTRACT}

Introduction: From pedicled TRAM flap to perforator based DIEP flap, all lower abdominal flaps cause varying degrees of abdominal wall morbidity. The results of a case series, where dermal graft produced from less perfused portions of these flaps in order to enhance fascial closure, have been presented.

Method: Retrospective chart review of 33 patients who underwent breast reconstruction between September 2012 and August 2016 has been performed. Demographic data, photographic documentation, operative notes, follow up visit notes and subjective evaluations of the patients in the long term have been gathered.

Results: The age of the patients ranged between 35 and 56 with an average of 43 . Twenty-two of the patients were premenopausal and 11 were postmenopausal. The BMI of the patients ranged between 26,2 and 34,6 with an average of 28,8 . Fourteen of the patients underwent immediate breast reconstruction and 19 of the patients underwent delayed breast reconstruction. Twentyone pedicled TRAM flaps, 5 free TRAM flaps, 4 free muscle-sparing TRAM flaps and 3 DIEP flaps have been performed. The followup period ranged between one year and three years with an average of 15 months. None of the patients experienced hernia formation in the follow-up period. In 2 patients, bulging of the donor area has been observed and in one of these two patients the fascial repair was performed. No infection or foreign body reaction has been observed in any of the patients. All of the patients reported normal active trunk flexion during daily activities.

Conclusion: The dermal "recycling" graft produced from poorly perfused parts of lower abdominal flaps yields satisfactory results with practical ease.

Keywords: Dermal, graft, breast reconstruction 


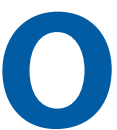

tolog meme rekonstrüksiyonunda alt karın duvarı flepleri son 30 yıldır artan sıklıkta kullanılmaktadır. Pediküllü TRAM (Transverse Rectus Abdominis) flep ile başlayan yolculuk serbest TRAM flep ile devam etmiş ve günümüzde karın duvarı elemanlarını çok daha fazla korumaya ve dolayısıyla karın duvarı stabilitesini olabildiğince az bozmaya yönelik perforatör bazlı DIEP (Derin Inferior Epigastrik Arter Perforatör) fleple devam etmektedir. Bu fleplerin donor alan kapamasında öncelik tahmin edileceği üzere fasya tamiri ve kas tamiridir. Bu amaçla söz konusu fleplerin giderek azalan miktarda fasya içermesi, derin fasyanın primer kapatılması ve ihtiyaç halinde sentetik meşlerin kullanılması yaygınlaşmıştır. Günümüzde sentetik meşler derin fasyanın primer tamirinin zor veya güvensiz olacağı hastalarda gerginliği azaltıcı olarak, daha nadiren de primer onarılan fasyanın üzerinde kuvvetlendirici bir tabaka olarak kullanılmaktadır. Benzer şekilde aselüler dermal matriksler de aynı amaçla kullanılabilmektedir. Alt karın kaynaklı fleplerle meme rekonstrüksiyonunda bir başka yaygın durum ise göreceli olarak az kanlanan ve dolayısıyla kullanılmayan flep kısmıdı. Seçilen ve kaldırılan flebin kaynak pedikülüne en uzak kısım olan bu kısım neredeyse her zaman kesilip atılır. Atılan bu kısmın derisinin dezepitelizasyonu ve lipektomisi sonucu ortaya çıkarılan dermal greftin yukarıda anılan sentetik meşler yerine kullanıldığı olgu serisi ve uzun dönem sonuçlar bu yazıda sunulmuştur.

\section{Hastalar ve metod}

Eylül 2012 ve Ağustos 2016 tarihleri arasında alt karın kaynaklı fleplerle meme rekonstrüksiyonu uygulanmış ve bu fleplerden elde edilen otolog dermal greftin donor alan kapamasında kullanıldığı toplam 33 kadın hastanın hasta dosyaları geriye dönük olarak incelenmiştir. Demografik bilgiler, fotografik dokümentasyon, ameliyat raporları, kontrol vizitlerinde tutulan notlar ve hastaların uzun döneme ait sübjektif değerlendirmeleri derlenmiştir.

\section{Cerrahi teknik}

Alt karın kaynaklı flep kaldırımasını takiben kaynak pediküle en uzak yaklaşık dörtte birlik kısım (Zon 4) dezepitelize edilir (Şekil 1). Bu kısmın flepten ayrılması ve steril masada bistüri veya disseksiyon makası ile lipektomisi sonrası elde edilen dermal "geri dönüşüm" grefti izotonik serum ile ıslatılıp sıkılmış nemli gazlı bez içinde steril masada muhafaza edilir. Flep transferi sonrası donor alanın kapatılması bilinen prensiplerle gerçekleştirilir. Fasya kapatımında pediküllü TRAM flep dahil olmak üzere fasya koruyucu bir yaklaşım gösterildiği için primer kapatım iki vaka haricinde mümkün olmuştur (Şekil 2). Bu iki vakada da dermal "geri dönüşüm" grefti fasya kenarları arasına "inlay" greft olarak yerleştirilmiştir. Buna ek olarak fasya tamirini kuvvetlendirici (reinforcement) amaçla hazırlanmış dermal "geri dönüşüm" grefti fasya tamirinin primer gerçekleştirildiği hastalarda tamir hattının üzerine "onlay" greft olarak uygulanmıştır (Şekil 3). Greft adaptasyonu, sentetik meşlerin aksine devamlı sütürasyonla değil, ayrı sütürlerle ve gerçekleştirilmiştir. Greftin ulaşabileceği maksimum gerginliğe yakın bir gerginlikte adaptasyon sağlanmıştır.

\section{Bulgular}

Eylül 2012 ve Ağustos 2016 tarihleri arasında alt karın kaynaklı fleplerle meme rekonstrüksiyonu uygulanmış toplam 33 kadın hastanın yaş aralığı 35 - 56 ve yaş ortalaması 43 idi. Hastaların 22'si premenopozal, 11'i postmenopozal idi. Hastaların vücut-kitle endeksleri 26,2 ile 34,6 arasında değişmekte ve ortalaması 28,8 idi. Hastaların 14 'üne eşzamanlı meme rekonstrüksiyonu, 19 'una geç meme rekonstrüksiyonu uygulanmıştı. Hastaların 21'ine pediküllü TRAM flep, 5 'ine serbest TRAM flep, 4'üne serbest kas koruyucu TRAM (MS-TRAM) flep ve 3 'üne serbest DIEP flep uygulanmıştı. Takip süreleri 1 yıl ile 3 yıl arasında değişmekte ve ortalama 15 ay idi. Hastaların hiçbirinde uzun dönemde herni gelişmedi (Şekil 4,5). İki hastada (\%6) donor alanda şişlik (bulging) tespit edildi ve bu hastalardan birinde reeksplorasyonla fıtık tamiri (\%3) yapıldı. Diğer hastada radyolojik ve klinik olarak fıtıkla uyumlu tablo bulunmadığı için takibe devam edildi.

Hastaların hiçbirinde enfeksiyon veya yabancı cisim reaksiyonu gelişmedi. Kontrol vizitlerindeki sorgularında hastaların tümü aktif karın fleksiyonu gerektiren günlük olaylarda (örn. sabah yatakten kalkarken) ameliyat öncesine göre herhangi bir zorluk yaşamadıklarını ifade etmişlerdir.

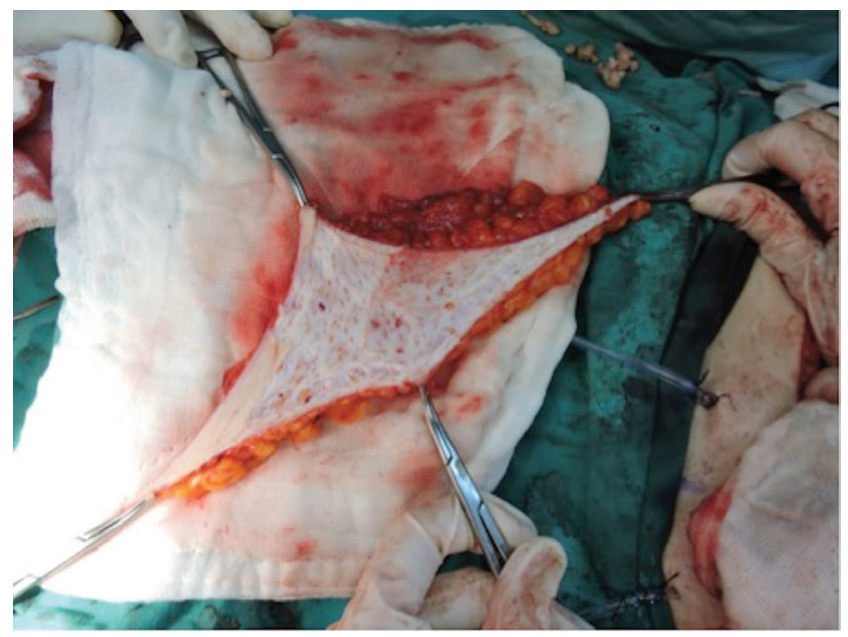

Şekil 1. Flebin Zon 4 bölgesi eksize edildikten sonra dezepidermizasyonunu gösteren perioperatif fotoğraf. 


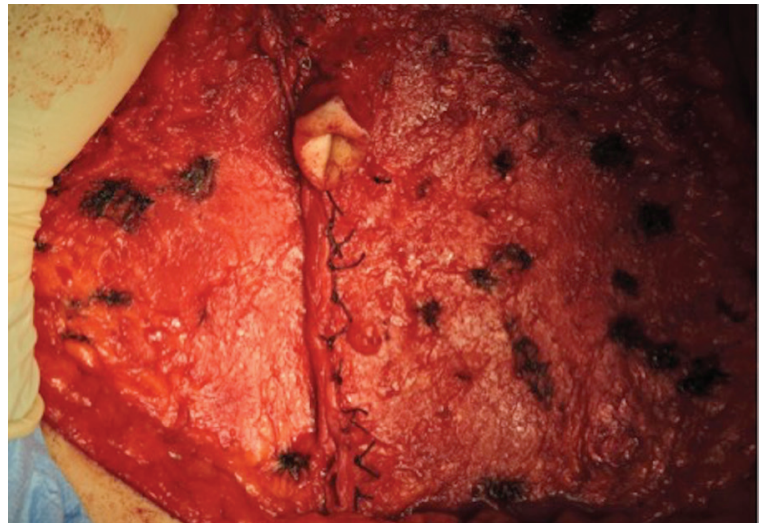

Şekil 2. Rektus fasiasının primer onarımı sonrası perioperatif fotoğraf.

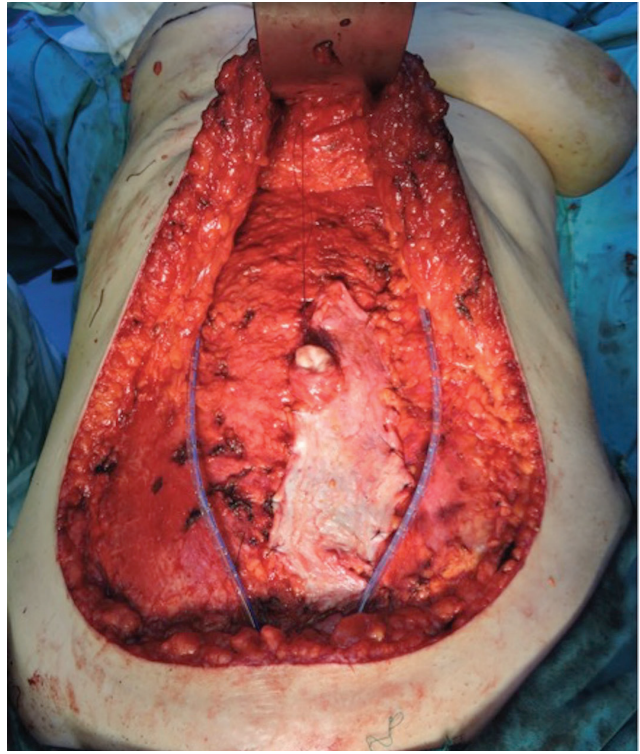

Şekil 3. Dermal "geri dönüşüm" grefti adapte edildikten sonraki perioperatif fotoğraf.

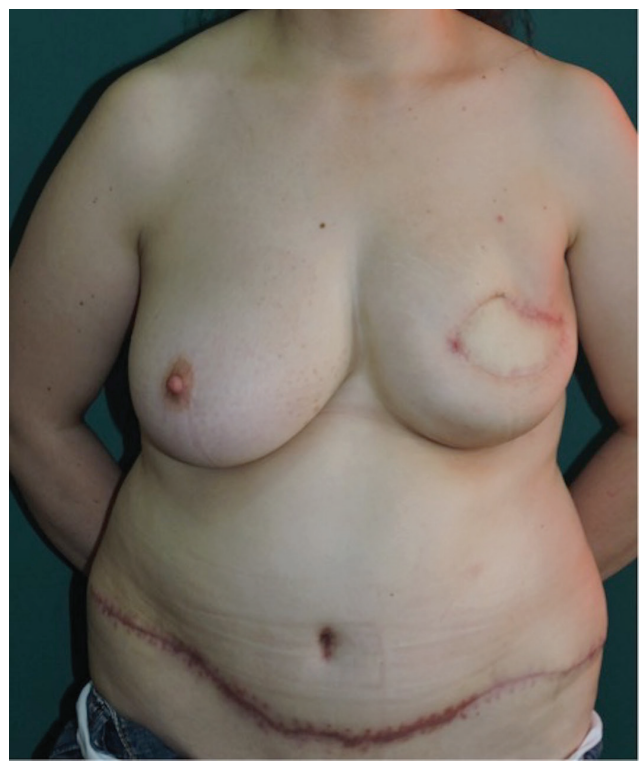

Şekil 4. Post-op 1 yıl sol frontal fotoğraf. Donor alanda hipertrofik skar mevcut. Ancak fasial dehissans veya fitık yok.

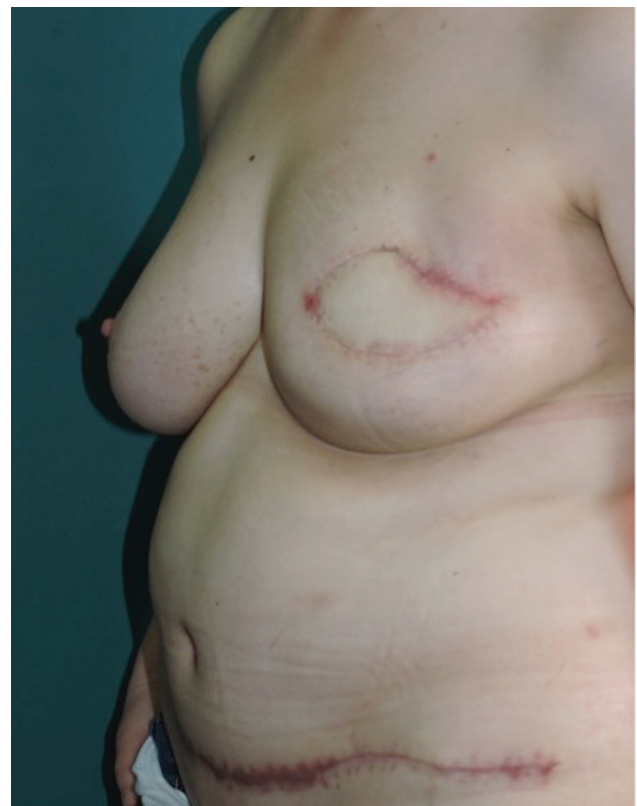

Şekil 5. Post-op 1 yıl sol lateral oblik fotoğraf. Donor alanda hipertrofik skar mevcut.

\section{Tartışma}

Otolog dokularla meme rekonstrüksiyonunda alt karın kaynaklı flepler tüm dünyada yaygın biçimde kullanılmaktadır. Pediküllü TRAM flebin tanıtılıp kullanılmaya başlanması sonrası bu fleple ilgili en önemli iki eleştiri flep perfüzyonunun yetersizliği ve donor alan morbiditesinin fazlalığı olmuştur (1). Bu eleştirilerle çağdaş dönemlerde mikrocerrahide yaşanan ilerlemeler TRAM flebin derin inferior epigastrik pedikül üzerinden kaldırılıp serbest aktarımına olanak tanımıştır (2). Sonrasında perforatör flep kavramının oluşması ve perforan disseksiyonu ile söz konusu flep derin inferior epigastrik perforanlar (DIEP) üzerinden kaldırılmış ve serbest olarak aktarılmaya başlanmıştır (3). Bu flep evrimi ile giderek az miktarda rektus kası ve fasyası sakrifiye edilmiş ve böylece karın duvarının primer onarımı mümkün olmuştur $(4,5)$.

Donor alan morbiditesini azaltmaya ve daha rafine flepler disseke etmeye yönelik bu çabalara rağmen DIEP fleple bile karın duvarında zayıflık yaşanabilmektedir (6). Keza kimi merkezlerde, fasya tamirinin primer yapıldığı olgularda bile kuvvetlendirici (reinforcement) amaçla sentetik meşler kullanılmaktadır (7). Bunun yanında aselüler dermal matriks son yıllarda aynı amaçla kullanılmaya çalışılmış bir üründür (8). Bu ürünle değişken sonuçlar bildirilmekle beraber aslında benzer ve hatta "daha otolog" bir materyal alt karın duvarı flep transferlerinde devamlı oluşmaktadır. Bu materyal, kaldırılan flebin perfüzyonunun en az olduğu ve dolayısıyla transfer edilmeyip atıldğı Zon4'ten çıkmaktadır. Bu bölümün dezepitelizasyonu ve lipektomisi ile oluşan 
dermal "geri dönüşüm" grefti alt karın duvarı kaynaklı flep donor alanı kapamasında kullanılmış ve ortalamanın üzerinde bir klinik fayda bildirilmiştir (9).

Sunulan 33 olguluk serimizde literatürle uyumlu olarak düşük bir komplikasyon oranı izledik. Bunun yanında literatürde belirtilene benzer şekilde başarılı bir klinik fayda profili elde ettik. Bu durum greftin elde edilmesi ve adaptasyonunda kullanılan cerrahi tekniğin başarılı olması ile açıklanabileceği gibi, olguların tamamına yakın bir kısmında bu greftin interpozisyonel bir "inlay" greft olarak değil de fasyanın primer kapatımına ek olarak kuvvetlendirici bir "onlay" greft olarak kullanılmasına bağlanabilir. Gerçekten de, seride kaldırılan tüm fleplerde fasya koruyucu bir yaklaşım sergilenmiştir. Bunun bir sonucu olarak, 21 pediküllü TRAM flebin donor alanı olguların ikisi $(\% 9,5)$ dışında primer kapatılmıştır. Bu tercih ve yaklaşım, donor alan stabilitesinde önceliği yardımcı materyallere değil fasya korumaya vermiştir. Böylece elde edilen dermal" geri dönüşüm " grefti fasya veya sentetik meşlerin yerini tutmak yerine primer fasya onarımına destek olacak bir materyal olarak kullanılmışır. Literatürdeki genel eğilim, aselüler dermal matriks gibi bir materyalin sentetik meşlerin yerini tutabilmesi amacına yönelik olmuş ve ne yazık ki bu materyal karın duvarı stabilitesi açısından geride kalmıştır.

\section{Kaynaklar}

1. Bharti G, Groves L, Sanger C, Thompson J, David L, Marks M. Minimizing donor-site morbidity following bilateral pedicled TRAM breast reconstruction with the double mesh fold over technique. Ann Plast Surg 2013;70:484-7. [CrossRef]

2. Yamada A, Harii K, Hirabayashi S, Kawashima T, Asato H. Breast reconstruction with the free TRAM flap after breast cancer surgery. J Reconstr Microsurg 1992;8:1-6. [CrossRef]

3. Hamdi M, Weiler-Mithoff EM, Webster MH. Deep inferior epigastric perforator flap in breast reconstruction: experience with the first 50 flaps. Plast Reconstr Surg 1999; 103: 86-95.

4. Futter $\mathrm{CM}$, Webster $\mathrm{MH}$, Hagen S, Mitchell SL. A retrospective comparison of abdominal muscle strength following breast reconstruction with a free TRAM or DIEP flap. Br J Plast Surg 2000;53:578-83. [CrossRef]

5. Uda H1, Kamochi H, Sarukawa S, Sunaga A, Sugawara Y, Yoshimura K. "Clinical and quantitative isokinetic comparison of abdominal morbidity and dynamics following DIEP versus muscle-sparing free TRAM flap breast reconstruction". Plast Reconstr Surg. 2017 Aug 3. [CrossRef]
Bu çalışmanın bazı limitasyonları da bulunmaktadır. En temel limitasyon retrospektif bir seri olması ve böylece ancak 4. seviye kanıt düzeyi (Level 4 evidence) bulunmasıdır. Bunun yanında olgu sayısı benzer yayınlarla karşılaştıııldığında az olmamakla birlikte geniş bir seri nitelendirmesi de yapılamaz. Son olarak, olguların takip sürelerinin daha uzun olması sonuçların daha objektif değerlendirmesini sağlayabilirdi.

Sonuç olarak, alt karın duvarı fleplerinin karın duvarı stabilitesi üzerine değişen oranlarda olumsuz etkisi bulunmaktadır. Bu etkiyi minimize etmek için hem fleplerin tasarımı zaman içinde daha rafine hale gelmiştir, hem de donor alan kapatımında sentetik ve allojenik materyaller denenmiştir. Bu fleplerin kullanılmayan kısmından elde edilen dermal greftler de akılda tutulması gereken materyallerdendir. Bizim elimizde bu greftler, primer fasya kapatımına ek olarak kuvvetlendirici (reinforcement) amaçla kullanılmış ve kabul edilebilir sonuçlar yakalanmıştır.

\section{Sonuç}

Alt karın duvarı kaynaklı fleplerin kullanımayan kısmından (Zon4) hazırlanan dermal "geri dönüşüm" grefti bu fleplerin donor alanının tamirinde pratik ve başarılı sonuçlar ortaya koymaktadır.

6. Beugels J, Hoekstra LT, Tuinder SM, Heuts EM, van der Hulst RR, Piatkowski AA. Complications in unilateral versus bilateral deep inferior epigastric artery perforator flap breast reconstructions: A multicentre study. J Plast Reconstr Aesthet Surg 2016; 69:1291-8. [CrossRef]

7. Wan DC, Tseng CY, Anderson-Dam J, Dalio AL, Crisera CA, Festekjian $\mathrm{JH}$. Inclusion of mesh in donor-site repair of free TRAM and musclesparing free TRAM flaps yields rates of abdominal complications comparable to those of DIEP flap reconstruction. Plast Reconstr Surg 2010;126: 367-74. [CrossRef]

8. Glasberg SB, D'Amico RA. Use of regenerative human acellular tissue (AlloDerm) to reconstruct the abdominal wall following pedicle TRAM flap breast reconstruction surgery. Plast Reconstr Surg. 2006;118:8-15. [CrossRef]

9. Kheradmand AA, Novin NR, Omranipour R. The use of dermal autograft for fascial repair of TRAM flap donor sites. Acta Med Iran. 2010;48:111-6. 